minute in every thirty, and so also is washing of the bitten surface. Recommendations for further treatment when the patient reached a doctor were the proper immobilization of the affected part, the injection of $100 \mathrm{mg}$. of hydrocortisone intramuscularly, the administration of a large dose of penicillin, a dose of tetanus antitoxin or booster dose of tetanus toxoid, and the gradual release of the ligature.

\section{MENTAL DISORDER IN OLD AGE}

Some time ago the Minister of Health ${ }^{1}$ made some surprising predictions about the much-reduced need, within the next 10 or 15 years, for accommodation for patients in mental hospitals. Official policy based on these forecasts is to be seen in the Ministry of Health's Hospital Plan, ${ }^{2}$ for psychiatric hospitals are to be reduced in size and several large ones are to go. Changes in the attitude of the public and methods of treatment which are making it possible for younger mental patients to return to more or less ordinary life are most welcome. But are there going to be enough beds to meet the needs of mentally frail old people, especially those suffering from senile psychoses? These cases are steadily increasing as the proportion of elderly people in the population becomes greater. Senile psychosis responds disappointingly to any form of treatment, and has the habit of progressing to dementia. Quite early in their disease these unfortunate patients hecome incapable of subsisting on their own: later their tendency to wander and to become intractable in behaviour and degenerate in personal habits makes them unacceptable in residential homes and an intolerable burden for the family at home. Most of them have an expectation of life of several months, but some survive for years. For most of that time they need constant supervision and competent, sympathetic nursing. In short, they qualify for long-term hospital care. Where will they go ?" Those elderly patients who are no more than eccentric, confused, and forgetful may be catered for in the special residential homes envisaged by the Mental Health Act, but few of these are beyond the planning stage. Meanwhile it appears that some existing mental hospitals, adopting a new interpretation of their functions under the same Act, are already declining to admit elderly people with incurable disorders. ${ }^{3}$. The long-stay wards of other hospitals, now part of active geriatric departments, are being asked to take more and more old people whose disabilities are mental, not physical. There is a great danger that their primary function-that of treating and rehabilitating old people with organic diseases or providing long-term nursing care when their efforts are unsuccessful-will be overborn by the weight of senile mental disorder they bear. Geriatric departments therefore have more occasion to be selective than mental hospitals. The final answer may be to

\footnotetext{
1 See Brit, med. J., 1961, 1, 820.

2 A Hospital Plan for England and Wales, 1962. H.M.S.O., London.

3 Andrews, J., The Times, May 3, $19 \% 2$.

- Andrews, J. D. B., and Insley, M. L.. Geront. clin. (Basel), 1962, 4, 94.
}

establish special psychiatric annexes in existing geriatric hospitals. Even now large numbers of mentally disturbed old people are being cared for by members of their families at great sacrifice of liberty and peace of mind. It is not reasonable that the hospital service should abdicate this responsibility either in the present transitional period or in the future, when a set policy of reducing beds in mental hospitals may have the effect of turning more and more private individuals into amateur geriatric psychiatric nurses. Some practical recommendations on the type of accommodation needed for "senile wanderers" have recently been put forward by J. D. B. Andrews and M. L. Insley, ${ }^{4}$ who estimate that a home for 50-70 residents would meet the needs of a population of 327,500 .

\section{" ETHIOPIAN MEDICAL JOURNAL"}

The Ethiopian Medical Association was founded very recently-the final letter authorizing its establishment was received on July 20 this year-and it has now produced the first issue of its official quarterly publication, Ethiopian Medical Journal. This issue, in English, is dedicated to Haile Selassie I, Emperor of Ethiopia and patron of the E.M.A., and it includes a message from him wishing the "E.M.J." every success. An article on health and medical problems points out that there are no vital statistics available for Ethiopia, but suggests that the expectancy of life there is probably not more than 35 years. There are about 200 physicians. working in the country, only 21 of whom are Ethiopians-about one per 100,000 inhabitants. There is no medical school at present, but one is planned for the Haile Selassie I University in Addis Ababa.

About 50 to $80 \%$ of the diseases in Ethiopia are estimated to be communicable and preventable. As Dr. B. Oscar Barry, chairman of the E.M.J.'s editorial board, writes in its first issue: "Medically, Ethiopia is, as yet, an untouched mine for research . . . clinical material there is in abundance, waiting for the trained observars to study, as well as to treat." One of the great sources of the Ethiopian Medical Association's strength, he believes, is the diverse tradition which it has inherited from the different medical schools of the world, and he looks forward to the day when, Ethiopia can provide her own doctors. Until then "the double processes of synthesis and growth combine to make medicine in Ethiopia both wonderfully interesting and tremendously exciting." The E.M.A.'s. address, and that of its journal, is P.O. Box 2179, Addis Ababa, Ethiopia, and contributions should be addressed there to the Chairman, Editorial Board, Ethiopian Medical Association, whose president is Dr. Fride Hylander.

Correction.-In the annotation "Diabetic Coma or Insulin Coma ?" (September 1, page 595) the second sentence inadvertently stated that mistakes are still sometimes made in differentiating hypoglycaemic coma "from the coma of insulin. overdosage." The last words should have been "from diabetic coma." 